\title{
Physical Model for GaN HEMT Design Optimization in High Frequency Switching Applications
}

\author{
D. Cucak, M. Vasic, O. Garcia, Y. Bouvier, J. Oliver, \\ P. Alou, J. A. Cobos
}

\author{
A. Wang, S. Martin-Horcajo, F. Romero, F. Calle
}

\begin{abstract}
In this paper, physical modeling of a GaN HEMT is proposed, with the objective of device design optimization for application in a high frequency DC/DC converter. From the point of view of a switching application, physical model for input, output and reverse capacitance as well as for channel resistance is very important, since the aforementioned parameters determine power losses in the circuit. The obtained physical model of the switching device can be used for simulation models such as PSpice or hybrid behavioral power loss models for high frequency DC/DC converters. In this work, extrinsic model for $I_{d}$ $\left(V_{d s}, V_{g s}\right)$ output characteristics of a depletion mode GaN HEMT with a field plate structure was obtained, as well as physical model for input, output and reverse capacitance in the subthreshold regime. The model was implemented in Simplorer simulation model and verified by the measured efficiency curves of the buck converter prototype, using the GaN HEMT that was analyzed. With the increase of the switching frequency, precision of the model increases, especially in the low power area, which is the area of interest in our application.

Keywords-GaN HEMTs; physical modeling; output characteristics, parasitic capacitances
\end{abstract}

\section{INTRODUCTION}

GaN based High Electron Mobility Transistors (HEMTs) are the most promising switching devices for high frequency applications [1]. Comparing to corresponding Si devices, their superior conductivity and switching characteristics give several times better Figure Of Merit [2], [3]. A significant progress in GaN HEMT design has been made, providing higher breakdown voltages and lower gate leakage currents by application of the field plate structure [4]. Also, big effort was made in the analysis of dynamic on-resistance and corresponding trapping effects [5].

High frequency DC/DC converter can be applied as a dynamic power supply for Radio Frequency Power Amplifier in Envelope Tracking and Envelope Elimination and Restoration Techniques. The topology that was considered in our work is a synchronous buck converter (Fig. 1) with GaN HEMTs employed as switching devices. Since wide bandwidth is a crucial feature of the converter, high switching frequency is needed. This implies importance of the physical model for input, output and reverse capacitance of the device, since they determine switching power losses and limit the switching speed. On the other hand, since the switching device operates in a linear part of the output characteristics, a model for on-resistance is necessary since this parameter determines conduction losses in the circuit. In order to obtain the relation between the power losses and switching device design, physical model is necessary. This was the main motivation in our work.

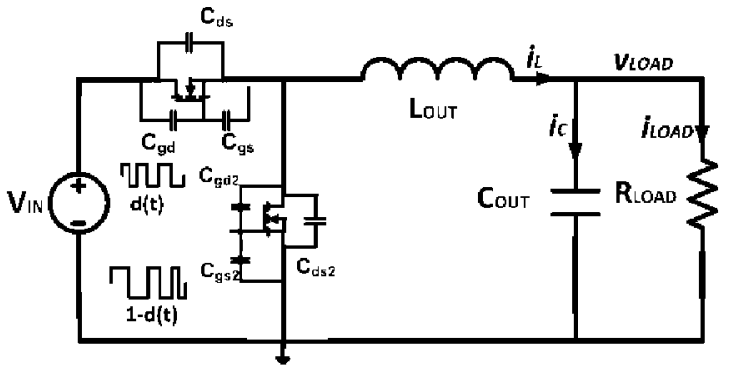

Fig.1. Synchronous buck converter with applied switching devices

\section{2 DEG SHEET DENSITY DEPENDENCE ON THE APPLIED GATE VOLTAGE}

The starting point for the physical model of a GaN HEMT is the charge control by the Schottky gate. Assuming that the 2DEG is being formed in a triangular quantum well, with only the first two subbands $E_{0}$ and $E_{1}$ possibly occupied, the 2DEG can be presented using Fermi-Dirac statistics as [6]

$$
n_{2 D E G}=D k_{B} T\left[\ln \left(1+e^{\frac{\left(E_{F}-E_{0}\right)}{k_{B} T}}\right)+\ln \left(1+e^{\frac{\left(E_{F}-E_{1}\right)}{k_{B} T}}\right)\right]
$$

where $n_{2 D E G}$ is the 2DEG sheet density, $D=4 \pi m_{l e}{ }^{*} / h^{2}$ is the density of states for each subband, $\mathrm{k}_{\mathrm{B}}$ is the Boltzmann's constant, $\mathrm{m}_{\mathrm{le}}{ }^{*}$ is the longitudinal effective mass of electron (= $0.22 \mathrm{~m}_{\mathrm{e}}$ with $\mathrm{m}_{\mathrm{e}}$ as the electron mass), $\mathrm{h}$ is the Planck's constant, $\mathrm{T}$ is the temperature and $\mathrm{E}_{\mathrm{F}}$ is the Fermi energy. The aforementioned subbands $\mathrm{E}_{0}$ and $\mathrm{E}_{1}$ are related to the $2 \mathrm{DEG}$ density as: $E_{0}=\lambda_{0} n_{2 D E G}{ }^{2 / 3}, \quad E_{1}=\lambda_{1} n_{2 D E G}{ }^{2 / 3}$ in $(\mathrm{eV})$, with $\lambda_{0}=2.123 * 10^{-12}$ and $\lambda_{1}=3.734 * 10^{-12}[6]$.

If we assume that gate and heterojunction depletion areas are overlapped resulting in total depletion of $\mathrm{AlGaN}$ layer, we can apply Poissons equation to $\mathrm{AlGaN}$ and GaN layer, together with Gauss's law for charge conservation at the AlGaN/GaN 
heterojunction (Fig. 2). This results in the following equation for $2 \mathrm{DEG}$ sheet density, $\mathrm{n}_{2 \mathrm{DEG}}$ :

$$
n_{2 D E G}=\frac{\varepsilon_{a}(m)}{q\left(d_{d l}+d_{s p}\right)}\left(V_{g}-V_{t h}(m)-\frac{E_{F}}{q}\right)
$$

where $m$ is the $\mathrm{Al}$ mole fraction in $\mathrm{Al}_{\mathrm{m}} \mathrm{Ga}_{(1-\mathrm{m})} \mathrm{N}, \varepsilon_{\mathrm{a}}(\mathrm{m})$ is the permittivity of $\mathrm{Al}_{\mathrm{m}} \mathrm{Ga}_{(1-\mathrm{m})} \mathrm{N}, \mathrm{d}_{\mathrm{d}}$ and $\mathrm{d}_{\mathrm{sp}}$ are the thickness of doped and spacer layer in $\mathrm{AlGaN}$, respectively, $\mathrm{V}_{\mathrm{g}}$ is the applied gate voltage and $\mathrm{V}_{\text {th }}$ is the threshold voltage given by the following equation

$$
V_{t h}(m)=\phi_{S}(m)-\Delta E_{C}(m)-\frac{q N_{D} d_{d}^{2}}{2 \varepsilon_{a}(m)}-\frac{\sigma_{P Z}(m)}{\varepsilon_{a}(m)}\left(d_{d}+d_{s p}\right)
$$

In the previous equation, $\phi_{S}(m)$ is the height of the Schottky barrier at gate- $\mathrm{AlGaN}$ heterojunction $(1.165 \mathrm{~V}), \Delta E_{C}(m)$ is the conduction band discontinuity at the $\mathrm{AlGaN} / \mathrm{GaN}$ interface (the height of the quantum well) equal to $0.343 \mathrm{~V}$ while $\sigma_{P Z}$ $(m)$ is the polarization-induced charge density of $0.0105 \mathrm{C} / \mathrm{m}^{\wedge 2}$ and is calculated using [6]. For the analyzed GaN HEMT, Eq. (3) gives a threshold of $-2.0899 \mathrm{~V}$ which is in good agreement with the measured value of $-2 \mathrm{~V}$. In order to obtain the Fermi level dependence on the applied gate voltage, model from [7] was used to approximate (1) for different relative positions of $\mathrm{E}_{\mathrm{f}}, \mathrm{E}_{0}$ and $\mathrm{E}_{1}$. In that way, the 2DEG dependence on the gate voltage is obtained and presented in Fig 3 .

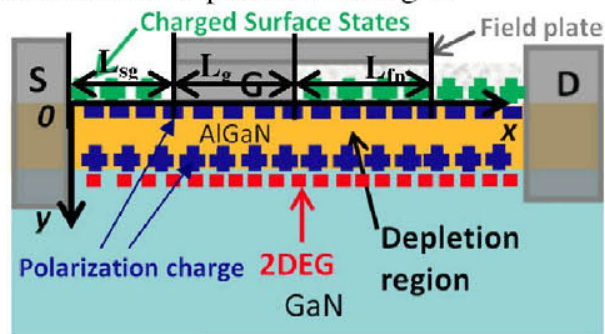

Fig.2. Cross section of a GaN HEMT with a field plate

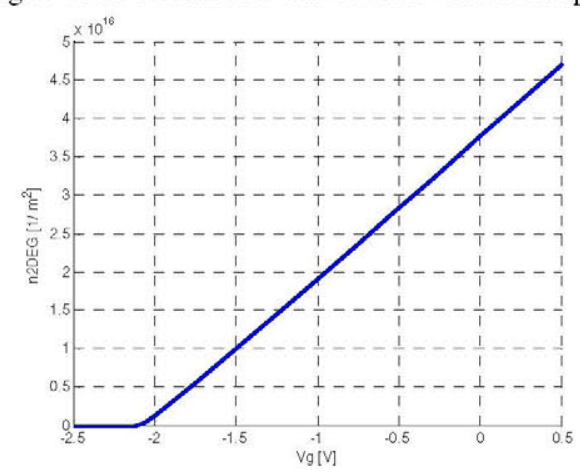

Fig. $32 \mathrm{DEG}$ sheet density control by the gate voltage, for $\mathrm{V}_{\mathrm{ds}}=0$

\begin{tabular}{|c|c|c|c|c|c|c|c|c|}
\hline $\begin{array}{c}\mathbf{W}_{\mathrm{g}} \\
{[\mathrm{mm}]}\end{array}$ & $\begin{array}{c}\mathbf{L}_{\mathrm{g}} \\
{[\mathrm{um}]}\end{array}$ & $\begin{array}{c}\mathbf{L}_{\mathrm{sg}} \\
{[\mathrm{um}]}\end{array}$ & $\begin{array}{c}\mathbf{L}_{\mathrm{fp}} \\
{[\mathrm{um}]}\end{array}$ & $\begin{array}{c}\mathbf{t}_{\mathrm{ox}} \\
{[\mathrm{nm}]}\end{array}$ & $\begin{array}{c}\mathbf{d}_{\mathrm{d}} \\
{[\mathrm{nm}]}\end{array}$ & $\begin{array}{c}\mathbf{d}_{\mathrm{sp}} \\
{[\mathrm{nm}]}\end{array}$ & $\begin{array}{c}\mathbf{m} \\
{[\%]}\end{array}$ & $\begin{array}{c}\mathbf{N}_{\mathrm{d}} \\
{\left[1 / \mathbf{m}^{3}\right]}\end{array}$ \\
\hline $\mathbf{1 2 0}$ & $\mathbf{2}$ & $\mathbf{2}$ & $\mathbf{1 . 5}$ & $\mathbf{8 0}$ & $\mathbf{2 0}$ & $\mathbf{3}$ & $\mathbf{2 5}$ & $\mathbf{1 0}^{\wedge 22}$ \\
\hline
\end{tabular}

Table 1. Parameters of the analyzed GaN HEMT with SiN field plate structure

\section{MODELING OF EXTRINSIC OUTPUT CHARACTERISTICS}

With 2DEG sheet density dependence on the gate voltage completed, it is possible to obtain the extrinsic $\mathrm{I}_{\mathrm{d}}\left(\mathrm{V}_{\mathrm{ds}}, \mathrm{V}_{\mathrm{gs}}\right)$ output characteristics of the HEMT. The drain current is modeled as [6]

$$
I_{d}=q W_{g} v_{D R I F T}(x) n_{2 D E G}(x)
$$

where $q$ is electron charge, $W_{3}$ is the gate width and $v_{\text {DRIFT }}(x)$ is the electron velocity given by

$$
\begin{array}{cc}
v_{D R I F T}(x)=\frac{\mu_{0}}{1+\frac{E(x)}{E_{C}}} E(x) & \text { for } E(x)<E_{C} \\
v_{D R I F T}=v_{S A T} & \text { for } E(x)>E_{C}
\end{array}
$$

In (5a), $E(x)=d V_{C}(x) / d x$ is the lateral electric field at any point $\mathrm{x}$ in the channel, $V_{C}(x)$ is the channel potential, $\mu_{0}$ is the low field mobility of $2 \mathrm{DEG}$ and is approximately equal to 1000 $\mathrm{cm}^{2} / \mathrm{Vs}, E_{C}$ is the critical electric field and $v_{S A T}$ is the saturation velocity of $3.775^{*} 10^{5} \mathrm{~m} / \mathrm{s}$. For linear region of operation we derive the expression for the drain current by solving (4) under the boundary conditions: $\mathrm{V}_{\mathrm{c}}\left(\mathrm{x}=\mathrm{L}_{\mathrm{sg}}\right)=\mathrm{I}_{\mathrm{d}} \quad\left(\mathrm{R}_{\mathrm{s} \mathrm{cm}}+\mathrm{R}_{\mathrm{s} \text { drift }}\right)$ and $\mathrm{V}_{\mathrm{c}}\left(\mathrm{x}=\mathrm{L}_{\mathrm{sg}}+\mathrm{L}_{\mathrm{g}}\right)=\mathrm{V}_{\mathrm{ds}}-\mathrm{I}_{\mathrm{d}} \quad\left(\mathrm{R}_{\mathrm{d} \_\mathrm{cm}}+\mathrm{R}_{\mathrm{d} \_ \text {drift }}\right)$. In the previous calculation, $\mathrm{R}_{\mathrm{s} \_\mathrm{cm}}$ and $\mathrm{R}_{\mathrm{d} \_\mathrm{cm}}$ are contact and metallization resistances of source and drain (approximately $25 \mathrm{~m} \Omega$ each), while $R_{d}$ drift and $R_{s \text { drift }}$ are drain and source drift resistances and they are modeled as

$$
R_{D \_ \text {DRIFT }}=\frac{L_{g d}}{q \mu_{0} W_{g} n_{S 0}} ; \quad R_{S_{-D R I F T}}=\frac{L_{g s}}{q \mu_{0} W_{g} n_{S 0}}
$$

In $(6 a, b) n_{S 0}$ is equal to the value of the 2DEG in the drift regions between source and the channel, and drain and the channel. This value corresponds to the value of $2 \mathrm{DEG}$ sheet density for gate voltage of zero volts. For the given geometry, we obtain $R_{\text {d_drift }}=54.8 \mathrm{~m} \Omega$ and $R_{\text {s_drift }}=27.4 \mathrm{~m} \Omega$.

The onset of saturation is defined when the electric field at the drain end of the channel (at $\mathrm{x}_{1}=\mathrm{L}_{\mathrm{sg}}+\mathrm{L}_{\mathrm{g}}$ ) reaches the critical value $E_{C}$ while the electron velocity reaches $v_{S A T}$. For drain voltages that are exceeding $\mathrm{V}_{\mathrm{dsat}}$, the point of saturation will move from the drain end (the point $\mathrm{x}_{1}$ ) towards source contact and the saturation current was modeled taking into account this channel length modulation [8]. The obtained extrinsic output characteristics are shown in Fig. 4. Observing the comparison with the experimental characterization of the device, it can be seen that the highest error of approximately $32 \%$ was found deeply in the saturation area, most likely due to additional effect of the field plate structure on the channel length modulation, which was not taken into account in the model. In the linear region, which is the area of interest for a switching application, a good agreement between the model and the measurements is observed.

\section{MODELING OF INPUT, OUTPUT AND REVERSE CAPACITANCE}

As it was already mentioned, dependences of input, output and reverse capacitance on drain-to-source voltage when the transistor is in the off-state $\left(\mathrm{V}_{\mathrm{gs}}\right.$ below the threshold value), are very important for the design of switching devices in high frequency applications.

In order to find the origin of Millers capacitance $\left(\mathrm{C}_{\mathrm{gd}}\right)$, we will observe the simulation of the 2DEG distribution in the channel, for $\mathrm{V}_{\mathrm{gs}}=-3 \mathrm{~V}$ and $\mathrm{V}_{\mathrm{ds}}$ being changed from 10 to $60 \mathrm{~V}$ (Fig. 5). It can be seen, that the main part of $2 \mathrm{DEG}$ leftover under the field plate is being depleted for $\mathrm{V}_{\mathrm{ds}}$ lower than $20 \mathrm{~V}$, caused by the electric field component perpendicular to the channel, $\mathrm{E}_{\mathrm{y}}$. On the other hand, lateral component of the electric field will provide additional extension of this depletion area in the whole range of $\mathrm{V}_{\mathrm{ds}}$. The simulation of the 
lateral component of the electric field, $\mathrm{E}_{\mathrm{x}}$, is presented in Fig. 6 . In order to physically model $2 \mathrm{DEG}$ depletion process under $\mathrm{E}_{\mathrm{y}}$ component, the following methodology was proposed. Since $\mathrm{V}_{\mathrm{gs}}$ is constant and $\mathrm{V}_{\mathrm{ds}}$ is being changed, the metalinsulator-semiconductor structure has been analyzed and its 2DEG sheet density dependence on the $\mathrm{V}_{\mathrm{gd}}$ was obtained. The closed form solution for this dependence is:
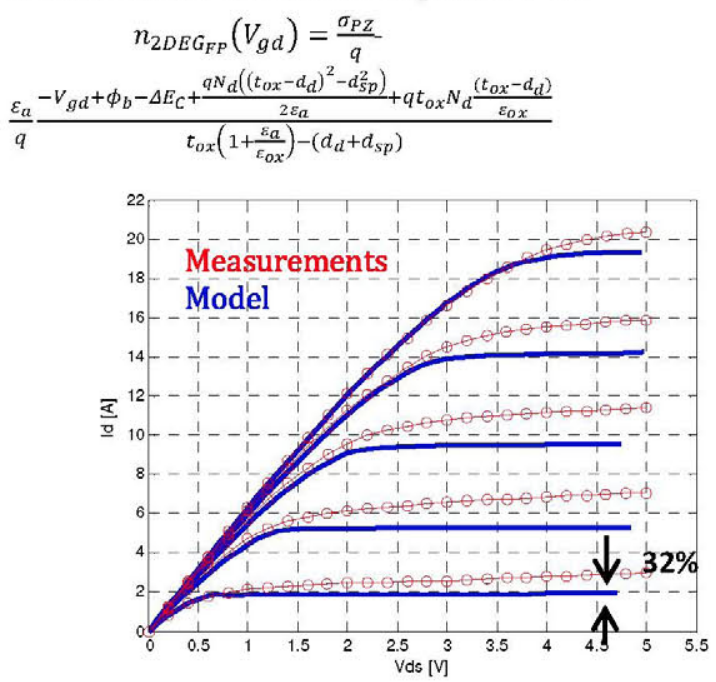

Fig.4. Extrinsic output characteristics of the HEMT: measured -red and modeled -blue

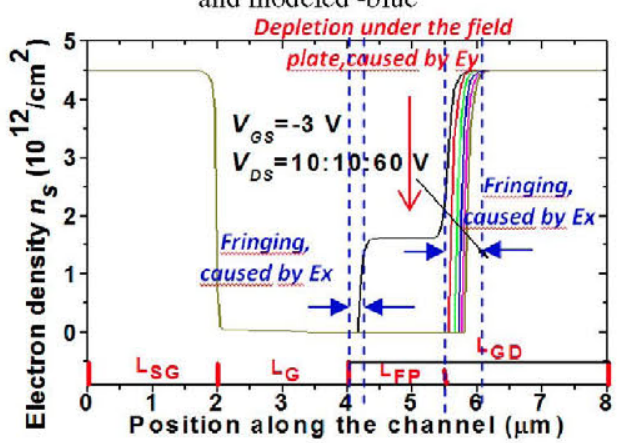

Fig.5. Simulation of 2DEG depletion in the channel, with increase in $\mathrm{V}_{\mathrm{ds}}$ from $10 \mathrm{~V}$ (black) up to $60 \mathrm{~V}$ (green), with a $10 \mathrm{~V}$ step

In (7), $\phi_{b}$ is the metal -insulator barrier height (equal to $2.2 \mathrm{~V}$ ), $t_{O X}$ and $\varepsilon_{O X}$ are the thickness and permittivity of the field plate. From (7), using $V_{g d}=V_{g s^{-}} V_{d s}$ and $C_{g d} \quad\left(V_{d s}\right)=q \quad L_{F P} W_{g}$ $d n_{D E G F I} / d V_{d s}$, we obtain the expression for the part of $\mathrm{C}_{\mathrm{gd}}$ caused by the $\mathrm{E}_{\mathrm{y}}, \mathrm{C}_{\text {gdy }}$ :

$$
C_{g d y}\left(V_{d s}\right)=L_{F P} W_{g} \frac{\varepsilon_{a}}{\left(t_{o x}\left(1+\frac{\varepsilon_{a}}{\varepsilon_{o x}}\right)-\left(d_{d}+d_{s p}\right)\right.}
$$

For $\mathrm{V}_{\mathrm{ds}}>16.5 \mathrm{~V}, \mathrm{C}_{\mathrm{gdy}}\left(\mathrm{V}_{\mathrm{ds}}\right)=0$. In the case of analyzed HEMT, this value is equal to $96.3 \mathrm{pF}$.

In order to model fringing of the depletion area in x-direction, conformal mapping technique has been used. In that way, depletion area extension dependence on the applied $\mathrm{V}_{\mathrm{ds}}$ has been obtained. In the range of drain voltages lower than $16.5 \mathrm{~V}$, this capacitance is added to the $\mathrm{C}_{\mathrm{gdy}}$ to obtain total Miller's capacitance, while for higher $\mathrm{V}_{\mathrm{ds}}$, this fringing part represents the total $\mathrm{C}_{\mathrm{gd}}$. The comparison between the obtained

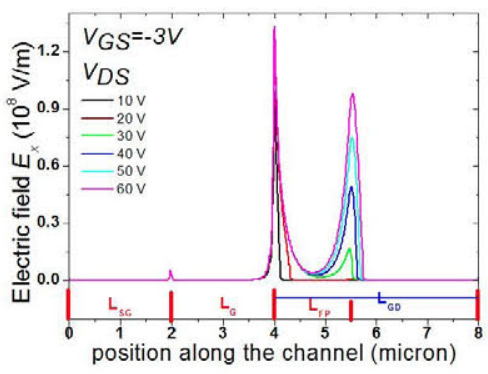

Fig.6. Simulation of lateral electric field in the channel

model and the measurements is presented in Fig.7. It can be seen that the knee voltage has been modeled precisely and that the highest error of $22 \%$ is obtained in the fringing area, where the capacitance values have the order of $\mathrm{pF}$.

Speaking of output capacitance, $\mathrm{C}_{\mathrm{oss}}=\mathrm{C}_{\mathrm{gd}}+\mathrm{C}_{\mathrm{ds}}$, it was necessary to determine the capacitance between drain and source terminal of the device. This capacitance mainly depends on the geometry of the device and how the metal layers are placed. In the case of the analyzed transistor, the main part of this capacitance is caused by the fringing between drain and source electrodes through GaN layer and for the given geometry is equal to $40 \mathrm{pF}$.

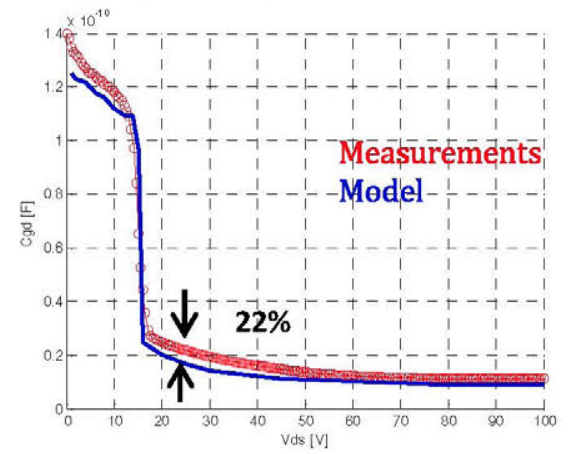

Fig.7. Modeled $\mathrm{C}_{\mathrm{gd}}$ (blue) versus measurements (red)

Gate to source capacitance also has the origin in the fringing between the electrodes through $\mathrm{AlGaN}$ layer (Fig. 8). The second important source of this capacitance is in the fringing between the metal pads that connect all gate and source fingers through $\mathrm{AlGaN}$ and $\mathrm{GaN}$ as well (Fig 9). The aforementioned capacitances have the values of 246 and $97 \mathrm{pF}$, respectively. As it can be seen from Fig. 10, the highest error of $40 \%$ in the capacitance model is found in the fringing area of $\mathrm{C}_{\text {oss }}$. Nevertheless, in absolute units this error is very small from the point of view of modeled application (HF DC DC converter), as it can be seen later. The modeled nonlinear capacitances are very important because they limit the "turn on/off" speed of the transistor that is used as a switch in this application. The slower the device the higher are the switching losses. Once the transistor is fully turned on, the losses are due to the current conduction and resistance of the metallization, contacts and the channel. The importance of obtained physical model of the device is that, through electrical model, it can be connected to a particular application (in our case HF buck converter) and subsequently, from the minimization of the power losses in the 
circuit, the optimization of the device design can be done. In [9], a hybrid behavioral-analytical power loss model for HF buck converter is presented and can be used as the aforementioned connection between the device physics and our application.

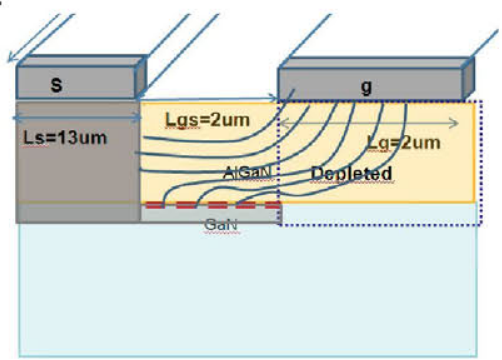

Fig. 8 Fringing between gate and source electrodes

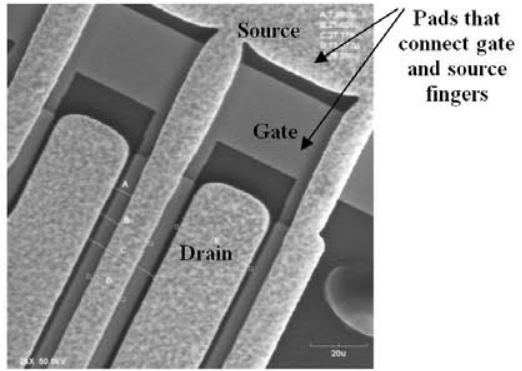

Fig. 9 Fringing between gate and source finger-connecting pads

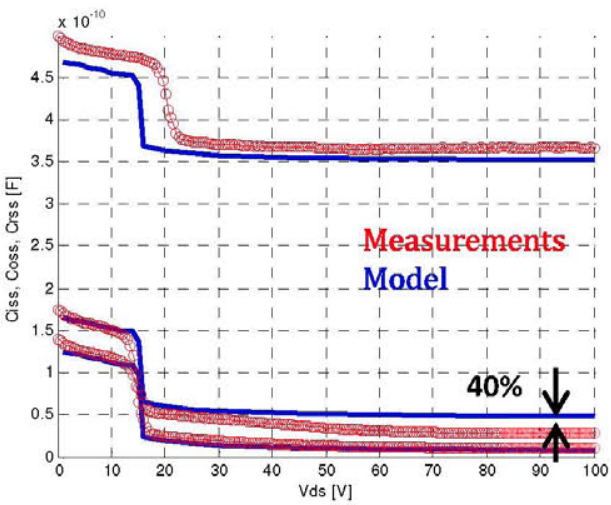

Fig. 10 Complete model versus measurements for $\mathrm{C}_{\mathrm{iss}}, \mathrm{C}_{\mathrm{oss}}$ and $\mathrm{C}_{\mathrm{rss}}$

In order to verify the proposed physical model, a high frequency buck converter with analyzed GaN HEMT has been built and tested at three different switching frequencies $(7,15$ and $20 \mathrm{MHz}$ ), changing the duty cycle in order to provide different output power levels. Measured efficiency curves are presented in Fig. 11, together with the simulated ones. Simulation was done in Simplorer, using the curves from previously presented physical model. It can be seen that good agreement between the simulation and the measurements has been obtained at each switching frequency.

\section{CONCLUSIONS}

Physical modeling of a GaN HEMT with field plate structure has been proposed in this paper. Obtained analytical model for

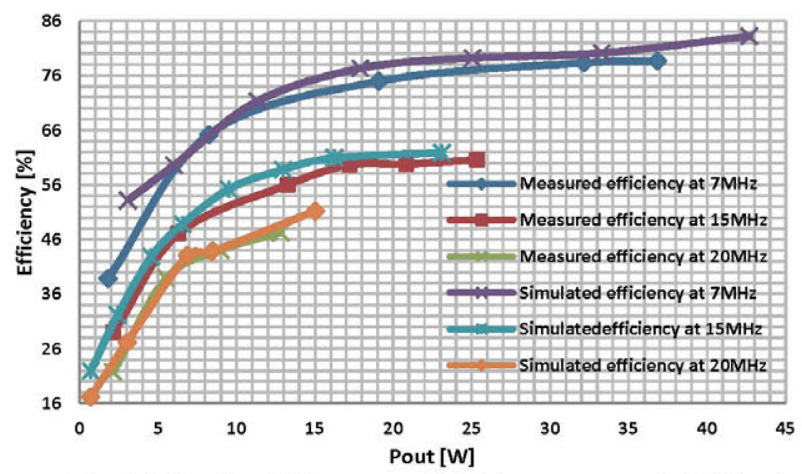

Fig. 11 Simulated Vs measured efficiency curves for HF buck

extrinsic output characteristics showed good agreement with the measurements in a linear part which is the area of interest in a switching application. On the other hand, input, output and reverse capacitance dependence on $\mathrm{V}_{\mathrm{ds}}$, in subthreshold regime has been obtained. Complete 2DEG depletion process was addressed and modeled. Different parts of the capacitances, caused by fringing between the electrodes and multifinger configuration of the device were established. Using the presented dependencies between the device capacitances and its geometry it is possible to optimize the width and length of the transistor gate, drain and source, and the number of paralleled fingers as well [10]. The obtained physical curves can be related to HF buck converter using hybrid PSpice model from [9]. Measured efficiency curves of a HF buck converter showed good agreement with simulated values at three different switching frequencies and verified the proposed model.

\section{REFERENCES}

[1] M. Rodriquez, Y. Zhang, D. Maksimovic, "High-frequency PWM Buck Converters Using GaN-on-SiC HEMTs" IEEE Trans. on Power Electronics, vol. 29, no. 5, pp. 2462-2473, May 2014

[2] http://epc-co.com/epc

[3] http://www.infineon.com/

[4] S. Karmaklar, M. S. Shur, G. Simin, M. A. Khan, "Field-plate Engineering for HFETs," IEEE Trans. on Electron Devices, vol. 52, no. 12, pp. 2534-2540, December 2005

[5] H. Huang, Y. C. Liang, G. S. Samudra, T. Chang, C. Huang, "Effects of Gate Field Plates on the Surface State Related Current Collapse in AlGaN/GaN HEMTs" IEEE Trans. on Power Electronics, vol. 29, no. 5, pp. 2164-2173, May 2014

[6] M. K. Chattopadhyay, Device Modeling of $\mathrm{AlGaN} / \mathrm{GaN}$ High Electron Mobility Transistors (HEMTs)- an Analytical Approach, Saarbruicken, Germany, LAP LAMBERT, 2010

[7] S. Khandewal, N. Goyal, T. A. Fjeldly, "A Physics -Based Analytical Model for 2DEG Charge Density in AlGaN/GaN HEMT devices"IEEE Trans. on Electron Devices, vol. 58, no. 10, pp 3622-3625, Oct 2011

[8] M. Saleh, M. Nokali, "A DC Model for the HEMT including the effect of parasitic conduction", in Proc. IEEE University/Government/Industry Microelectronics Simposium 1991, pp. 164-168

[9] D. Diaz, M. Vasic, O. Garcia, J. A. Oliver, P. Alou, J. A. Cobos, "Hybrid behavioral-analytical loss model for a high frequency and low load DC-DC buck converter", in Proc. IEEE Energy Conversion Congress and Exposition 2012 (ÉCCE), pp. 4288-4294.

[10] Reiner, R.; Waltereit, P.; Benkhelifa, F.; Muller, S.; Müller, S.; Walcher, H.; Wagner, S.; Quay, R.; Schlechtweg, M.; Ambacher, O. "Fractal structures for low-resistance large area $\mathrm{AlGaN} / \mathrm{GaN}$ power transistors," Power Semiconductor Devices and ICs (ISPSD), 2012 24th International Symposium on , vol., no., pp.341,344, 3-7 June 2012 